\title{
Simulation Model of a Node for Smart Grid Applications, Equipped with Photovoltaic Panel, Energy Storage and Electric Vehicle
}

\author{
Lorenzo Damiani, Jacopo Dellachà, Alessandro Pini Prato and Roberto Revetria
}

\author{
University of Genoa, Via Montallegro 1, 16145 Genoa Italy
}

\begin{abstract}
The improvement of renewable energy sources exploitation is a central topic of the present studies in the energetic field. One of the main obstacles to the renewable energy increase in the global energetic mix is represented by the fluctuating nature of renewable power sources. The power fluctuations are cause of stress for the electric grid to which the individual nodes are connected.

A wider exploitation of renewable power is possible through the implementation of a "smart grid", constituted by an interconnection of several smart nodes consisting in a user and a renewable source. To reduce the stochastic effects of the renewable energy source it is possible to introduce in the nodes composing the smart grid an energy storage, finalized to smooth the power peaks, rending the node itself less disturbing for the electric grid.

This paper presents a simulation model of a smart node, consisting in a user power profile, a photovoltaic panel, an electric vehicle and a battery. Through the simulation model it is possible to evaluate the node effect on the electric grid, with a quantitative approach.

Tests were worked out in different node configurations: basic (the only user power profile), basic with photovoltaic panel, basic with storage, basic with panel and storage and finally the complete configuration including also the electric vehicle. The tests were repeated for a domestic and an industrial user to evaluate the size influence over the parameters of interest.
\end{abstract}

Keywords: Smart grid, electrochemical storage, renewable energy, dynamic simulation, Matlab-Simulink.

\section{INTRODUCTION}

The global energy mix is today becoming more and more complex, unless fossil fuels remain the major source of energy employed. According to the present trend, renewable energy sources (RES) such as wind turbines and photovoltaic solar plants, but also biomass plants, hydropower turbines and others, will represent a consistent part of the future power generation system [1].

The introduction of an increasing amount of renewable energies in the mix is not immediate, since several problems need to be faced. The main issues regarding the integration of stochastic RES such as wind or sun within the electric grid is their variable and intermittent nature. Presently, this issue is faced by keeping in standby a certain number of fossil power plants (typically gas turbines) ready to supply the required power when sun or wind fall [1]. However, this is a poorly efficient solution, since fuel is required to keep the plants ready in idle conditions.

Another problem regards the integration of RES into grids at remote points [1], where grid weakness may be cause of unacceptable voltage variations due to power fluctuations.

*Address correspondence to this author at the University of Genoa, Via Montallegro 1, 16145 Genoa, Italy; Tel: + 393489194710

E-mail: Lorenzo.Damiani@unige.it
These issues can be overcome by the use of energy storage systems, which can compensate for the stochastic nature of the RES without the need of idling fossil fuelled power plants, while smoothing the power fluctuations [2].

In this paper a solution consisting in a smart grid composed by several smart nodes is taken in consideration. In the authors vision, each smart node should have its RES source and storage, the latter being sized according to the necessities and to the node characteristics (mainly the user expected power profile and the installed renewable power), so that the node seen from the grid results less onerous in terms of power distortion.

The paper focuses on the implementation of a simulation model of the smart node. The model is composed by several modules, namely the user profile, the photovoltaic panel, the electric vehicle and the storage. All these modules can be modified in their topical parameters in order to reproduce the operation of different sizes and typologies of smart-node.

The model is important to understand the behavior of the node in its different configurations, evaluating the main parameters of the system (such as the energy balance, the grid distortion factor, the stress on the battery) and searching for a correct operational algorithm to join together all the node components. 
Different tests were carried out to understand the behavior of the node in its configurations. Namely, the tests envisaged:

- the simulation of a node characterized by a typical domestic power profile, with a photovoltaic plant of $8 \mathrm{~m}^{2}$ paneled area (about 1 kW peak power);

- $\quad$ the simulation of the typical domestic node with a photovoltaic plant of $24 \mathrm{~m}^{2}$ paneled area (about $3 \mathrm{~kW}$ peak power);

- the simulation of a node dedicated to a small/medium enterprise industrial facility, with a photovoltaic plant of $80 \mathrm{~m}^{2}$ paneled area (about $10 \mathrm{~kW}$ peak power).

The tests were repeated in order to evaluate the effect of battery size and the influence of the electric vehicle presence (only for the domestic user simulations). So far, literature does not report similar simulation models applied to a smart-node system, nor are frequently published the results of a similar analysis.

The present research work has been carried out within the Alp-Store project, in the Alpine Space environment.

\section{THE SMART NODE SIMULATION MODEL}

Figure 1 represents the scheme of the plant comprising all its sub-systems: the user, the photovoltaic plant, the battery and the electric vehicle.
The components are joined together by an intelligent inverter, which converts the electric powers of all the sub-systems into the desired signal typology (AC or DC with the proper voltage), while deciding the amount of power to be delivered to the storage or that to be taken from the electric grid.

The smart node model was implemented in the Matlab Simulink environment. The model sample time was set to 1 minute [3], in order to correctly simulate the dynamic behavior of the system while keeping an acceptable runtime of the simulation (runtime is rather long owing to the long simulated time period, one month).

The model, named TRAMSE consists of three sections:

- pre-processing, in which the important data of the system are loaded (e.g. panel area, battery size, electric vehicle characteristics, algorithms for system control ...);

- $\quad$ processing, consisting in the calculations carried out by the simulation model.

post-processing, in which the results are provided as output. The system outputs are all the power flows and energy amounts interesting the different system modules, together with performance indicators of which a more detailed description will be given in the next sections.

In the following are described the sub-systems composing the smart-node model.
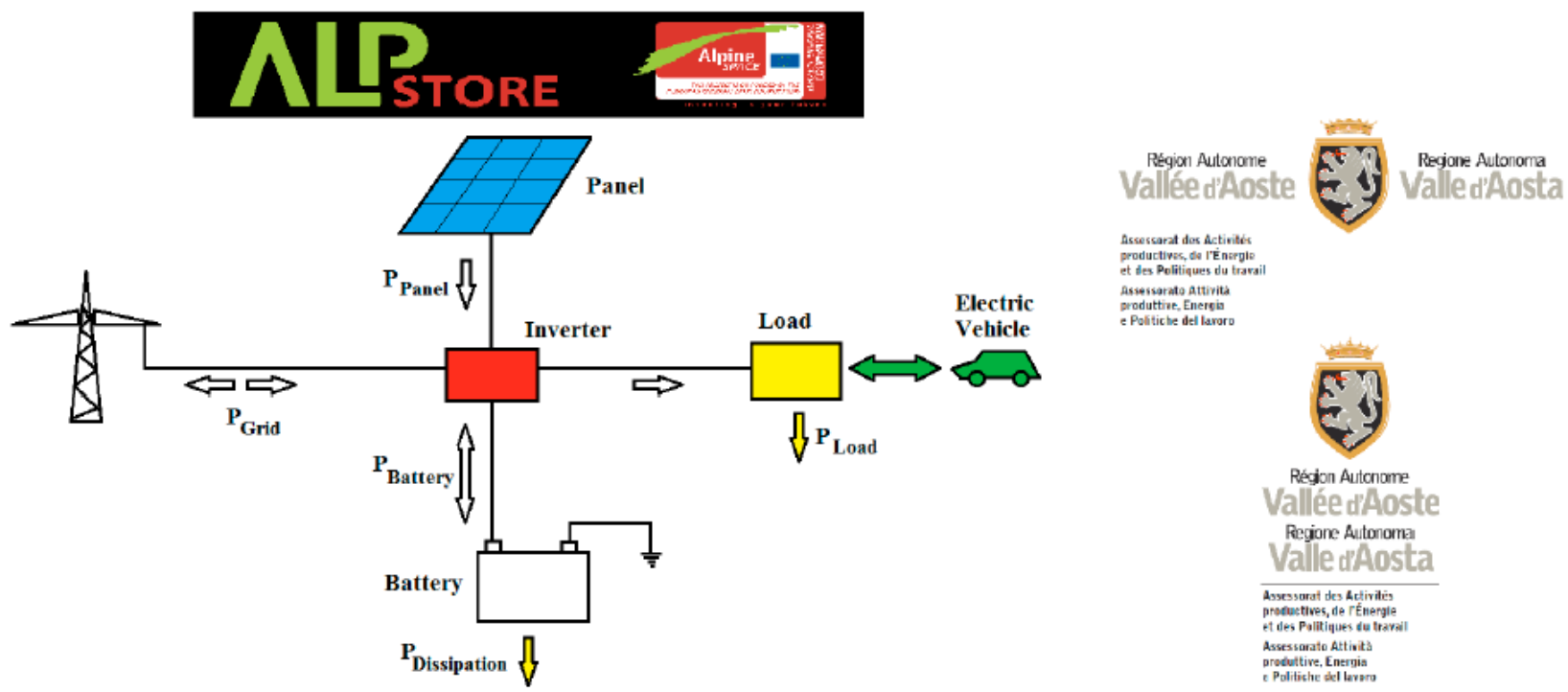

Figure 1: Scheme of the node physical connections. 


\subsection{Load}

The electric load for the domestic user was simulated through a series of Simulink "pulse generators", representing the power of the different electric loads present in a typical house. Each pulse generator produces a pulse with set amplitude, duration and phase. The sum of all the pulses, each with different phase, produces the signal represented in Figure 8. The load power values, durations and phases were opportunely set in order to obtain a signal the as similar to reality as possible, with power peaks not exceeding $3 \mathrm{~kW}$ and a total energy consumption of about $430 \mathrm{kWh}$ in one month. This result represents a typical family consumption, indicating that the power profile was set correctly in energetic terms.

For the industrial user, power values coming from on-field measurements were made available by a real plant; the measurements were taken with a sampling period of 1 minute, to match with the simulations. The industrial user has maximum absorbed power peaks of about $38 \mathrm{~kW}$ and a monthly consumption of $3274 \mathrm{kWh}$.

\subsection{Panel}

The panel model was built according to the modality described in [4]. To reduce the computational load for the simulator, the solar panel model above mentioned was employed to derive maps of voltage and current per panel square meter in function of sun irradiation and environmental temperature. Such maps were embedded in the TRAMSE simulator. Of course, the TRAMSE software can receive more precise mapped values, for example coming from experimental tests on a real panel.

Irradiation was calculated through a mathematical model of the solar radiation on the ground [5]; the model takes into account the geographical position of the photovoltaic plant so as its orientation with respect to the sun.

The radiation model also accounts for the presence of clouds, that reduce solar radiation to the ground. To simulate the cloudy sky, an algorithm was studied in order to produce the incidence of clouds; the algorithm is based on random numbers generators that reproduce the presence, the intensity and the duration of cloudy weather in function of the season.

The random number generators are set in order to produce numbers comprised between 0 and 1. As visible in Figure 2, they feed Simulink lookup-table blocks containing the weather functions. The latter contain the curves of the weather coefficient, which is comprised in the range between 0.2 (cloudy weather) and 1 (no clouds). The random number enters the lookup-table and, basing on the shape of the weather function, produces an output value. In this way, a random variation of the weather coefficient is obtained for the different seasons.

The produced coefficient variable multiplies the sun irradiation, in order to reduce it when the sky is cloudy.

\subsection{Electric Vehicle}

The electric vehicle behaves as a load which may be present or not in the energy system (see Figure 1). The electric vehicle model is built to provide to the system a random presence of the electric vehicle. This means that both the presence and the state of charge of the vehicle are represented as random variables. In fact, every time the vehicle battery is attached to the system, its state of charge can be different. The Simulink blocks have been set in order to obtain this effect.

When the vehicle is connected to the energy system, it behaves as a constant load (by hypothesis, it absorbs a power of $1 \mathrm{~kW}$, but different charging laws can be set) with a random value of the initial state of charge. As soon as the battery is charged, the vehicle load detaches from the system. The algorithm was implemented by the scheme in Figure 3.

\subsection{Electrochemical Stationary Storage}

To calculate instant by instant the value of the state of charge, the storage was modeled as an integrator Simulink block, whose input is the chemical power to/from the battery.

The chemical power comes from the instantaneous value of the gross power, which is calculated by the control algorithms. To determine the chemical power on the basis of the gross power, the battery efficiency needs to be known. The simulation model allows to set the efficiency curves of the battery in charging and discharging modes, in function of the parameter Power/Energetic Capacity [kW/kWh]; if said curves are not known, a single value of the efficiency can be set for charging and discharging.

In this work the curves of battery efficiency were determined by a Simulink model of the battery, described in [6-10]. 


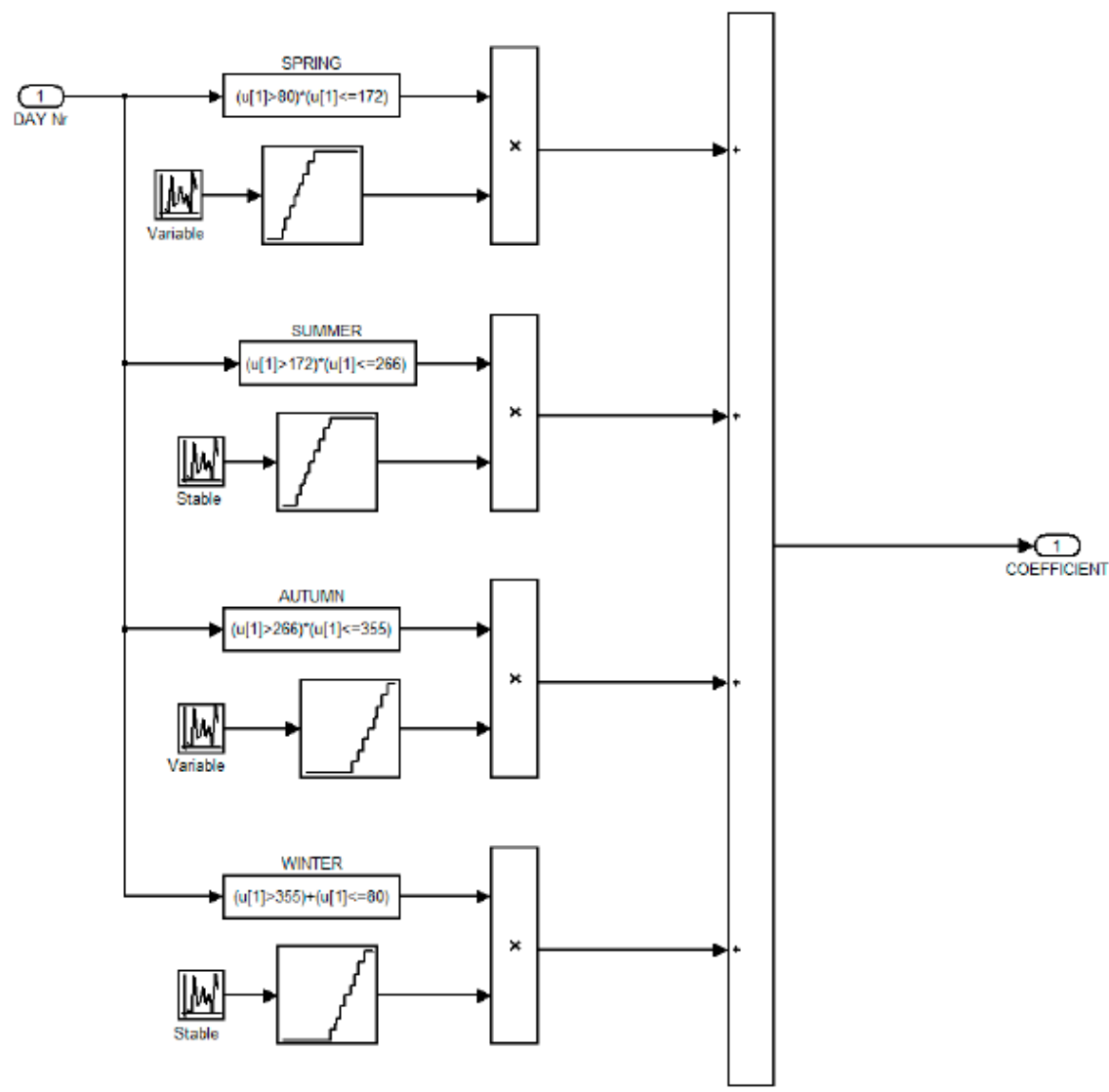

Figure 2: Generation of the cloudy sky coefficient, Simulink scheme.

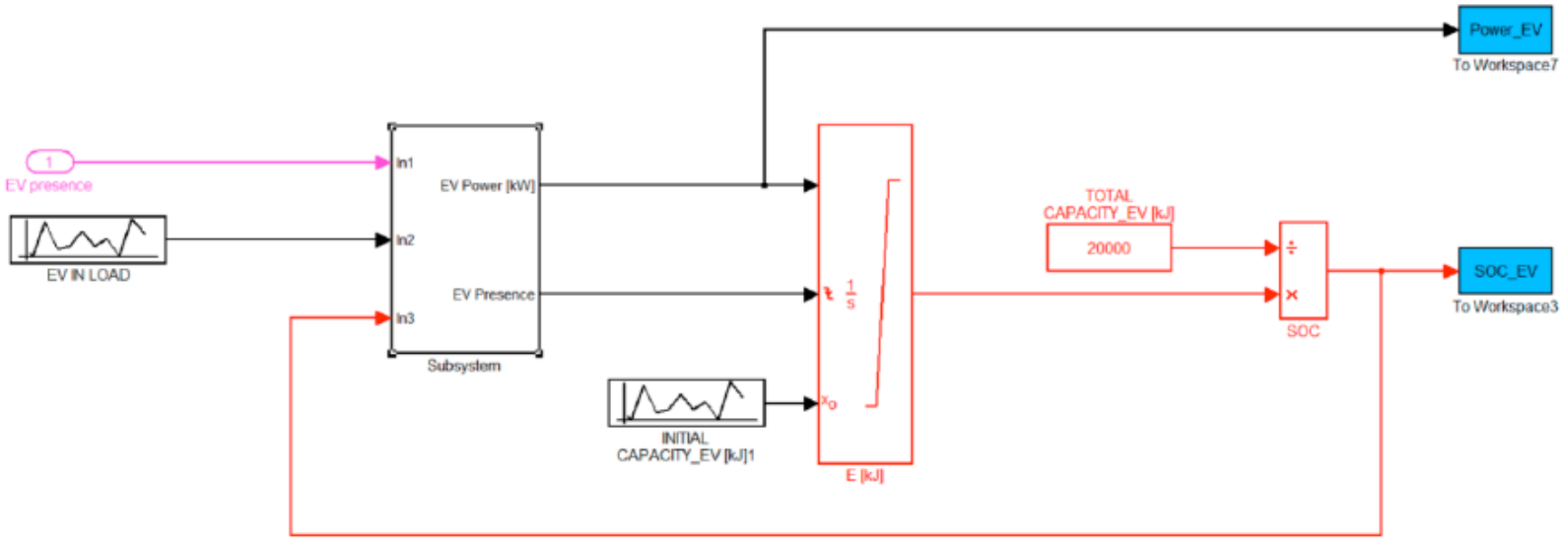

Figure 3: The electric vehicle, Simulink scheme.

In Figures $\mathbf{4}$ and $\mathbf{5}$ are represented the efficiency curves, in charge and discharge, of two commercial lead batteries employed for simulations, having energetic capacity of respectively 6 and $12 \mathrm{kWh}$. The efficiency curves, which were derived from the battery simulation model above referenced, include the inverter efficiency.

Also for the battery, if a curve derived from experimental data or more precise models is available, it can be embedded easily in the simulator.

\section{ALGORITHMS FOR SYSTEM POWER AND BATTERY SOC MANAGEMENT}

The system requires a control algorithm to determine the amount of power in input and output of the battery and the amount of power absorbed from the grid and that delivered to the grid. Such algorithm must be structured in order to maintain the battery state of charge at an acceptable level (e.g. between $35 \%$ and $95 \%)$. 


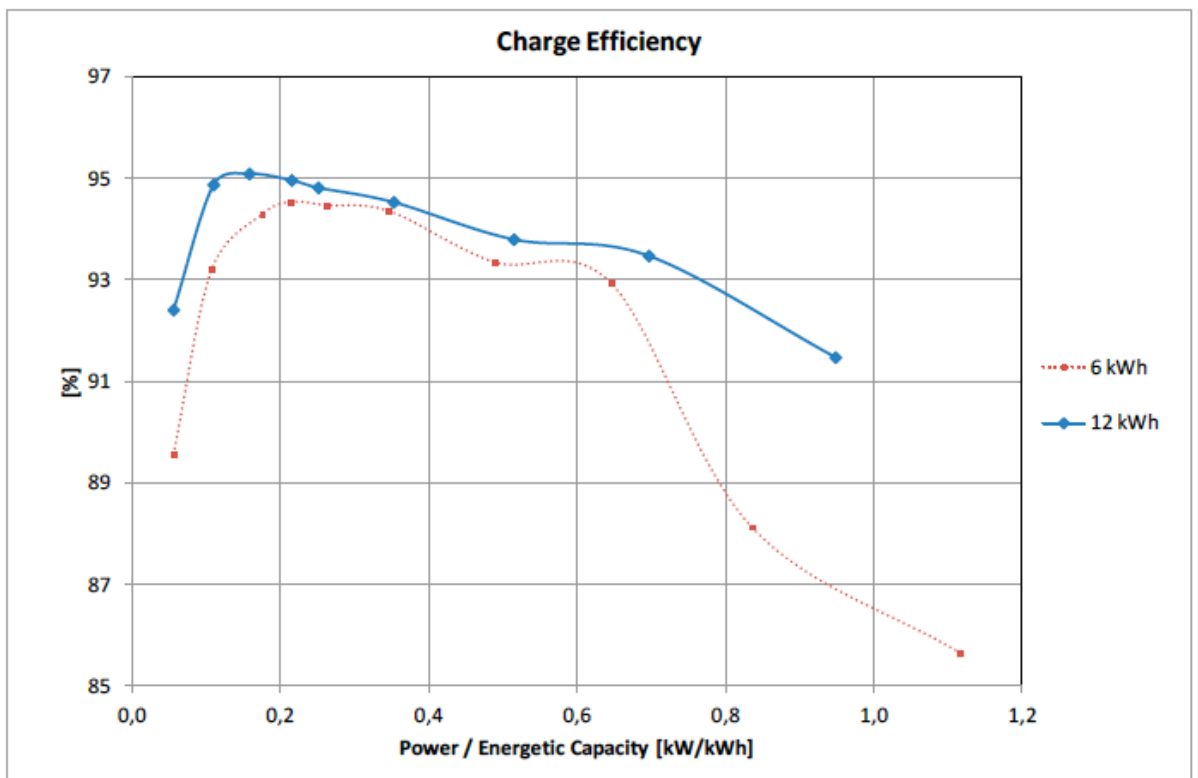

Figure 4: Efficiency curves for $6 \mathrm{kWh}$ and $12 \mathrm{kWh}$ energetic capacity batteries, during charging.

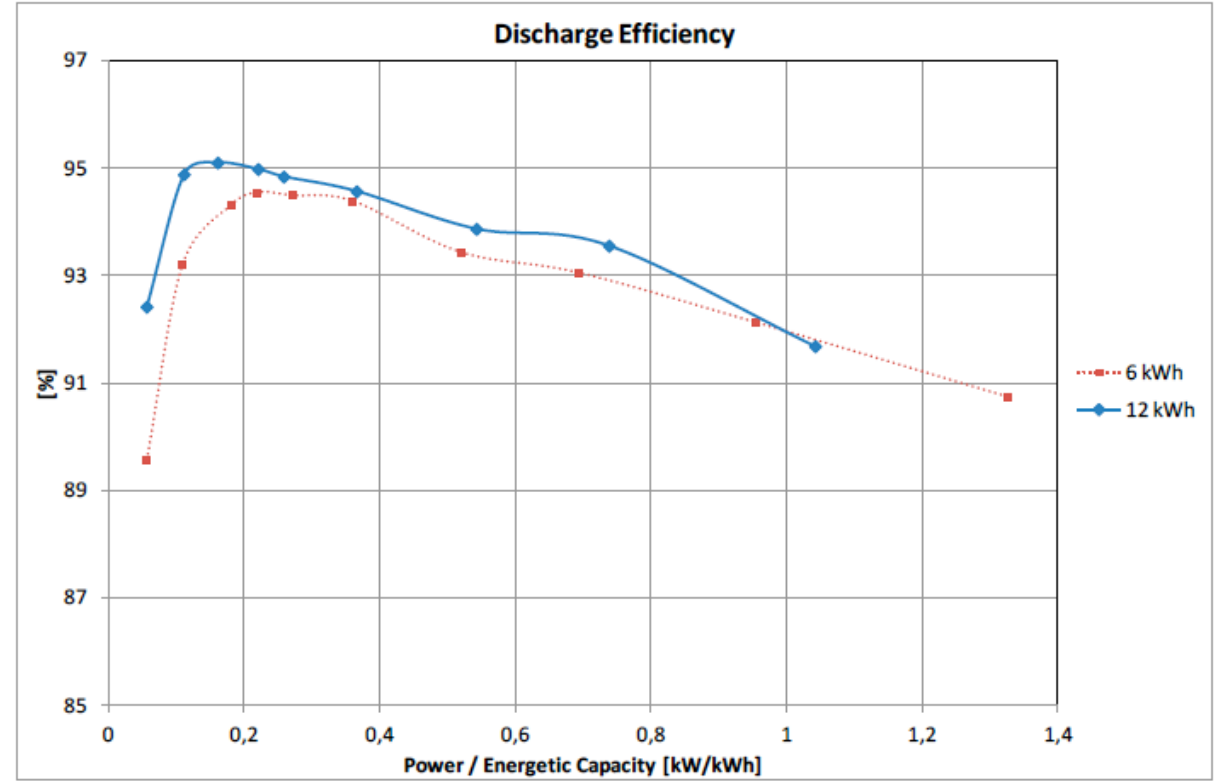

Figure 5: Efficiency curves for $6 \mathrm{kWh}$ and $12 \mathrm{kWh}$ energetic capacity batteries, during discharging.

The TRAMSE model was employed to evaluate different possible control logics of the system equipped with energy storage. Among the several possible control algorithms, two were chosen, of which the results are presented: one turned to the grid-smoothing and one to the self-consumption of the energy produced by the PV panel. The algorithm input parameters are:

- $\quad$ The algebraic sum of panel power and power required by the user $\left(\right.$ Delta $\left.=P_{\text {Panel }}+P_{\text {Load }}\right) ; P_{\text {Load }}$ is a quantity lower than zero according to the convention for which powers entering the system are positive, while powers exiting from the system (included the dissipations) are negative. Instead, $P_{\text {Panel }}$ is always positive or zero.

- $\quad$ The battery state of charge (SOC).

The algorithm output parameters are

- $\quad \mathrm{P}_{\text {Grid, }}$, the power taken from the grid if positive or delivered to the grid if negative.

- $\quad P_{\text {Battery, the battery input (positive) or output }}$ (negative) power. 


\subsection{Algorithm for Grid-Smoothing Mode}

If Delta is negative (i.e. the system behaves as a consumer, requiring power from the grid), the system responds to the following equations:

$$
\begin{aligned}
& P_{\text {Grid }}=P^{*}-P^{*}\left(\text { SOC } / S_{S O C^{*}}\right) \\
& P_{\text {Battery }}=P_{\text {Grid }}-\mid \text { Delta } \mid
\end{aligned}
$$

Equation (1) being a descending straight line, saturated to an upper value $\mathrm{P}_{\text {Lim }}$ as represented in Figure 6.

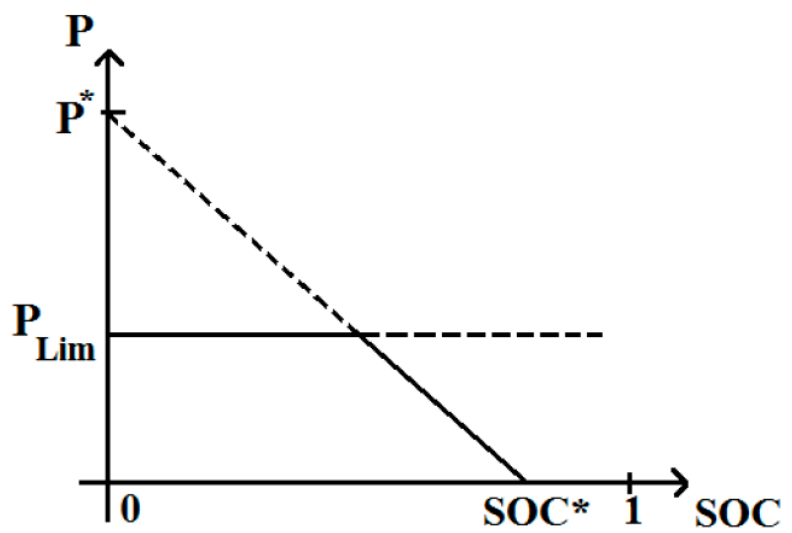

Figure 6: Curve for the grid-smoothing algorithm.

The equation values are set in order to provide a grid power equal to $\mathrm{P}_{\mathrm{Lim}}$ for the medium/low SOC values and a grid power function of the battery state of charge for the high SOC values. In this way, when the $\mathrm{SOC}$ is high the power required for the load satisfaction is taken from the battery, which is discharged, according to Equation (2).

According to Equation (2), the battery is charged when $\mathrm{P}_{\text {Grid }}>$ Delta, which occurs when the algebraic sum between user power and panel power is lower than the power taken from the grid. The battery is discharged when $\mathrm{P}_{\text {Grid }}<$ Delta.

If Delta is positive (i.e. the system has a surplus of power produced by the panel and behaves as a producer) the system responds to the following equations:

$P_{\text {Grid }}=$ Delta

$P_{\text {Battery }}=0$

Thus, all the surplus of power not exploited by the user is delivered to the grid, while no power enters or exits the storage.

\subsection{Algorithm for Node Self-Consumption Mode}

If Delta is positive, the following equations are implemented:

$P_{\text {Grid }}=0$

$P_{\text {Battery }}=$ Delta

Thus, when a power surplus exists, the difference between power produced by the panel and power required by the user is sent to the battery; no power, instead, is delivered to the grid.

If Delta is negative, the system operates according to Equations (7) and (8):

$$
\begin{aligned}
& P_{\text {Grid }}=- \text { Delta }+P_{\text {Battery }} \\
& P_{\text {Battery }}=P^{*}-k S O C
\end{aligned}
$$

Equation (8) being represented by the diagram in Figure 7, saturated with an upper saturation limit equal to 0 . When a power deficit exists (the panel produces less power than that required by the load), the load is fed by the storage power, which is function of the SOC according to the law represented in Figure 7. The remaining power is taken from the grid according to Equation (7).

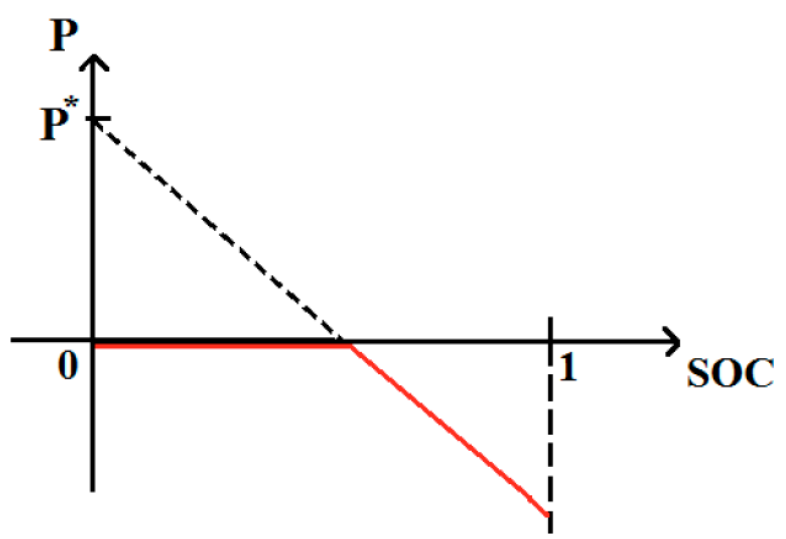

Figure 7: Curve for the self-consumption algorithm.

The two chosen algorithms for the control of the node behavior were chosen after a large number of different algorithms tests, carried out thanks to the simulation model.

\section{RESULTS}

In this section the results of the simulations are presented and commented. 
To understand the behavior of a smart node mostly finalized to the self-consumption of the energy produced by the panel, tests were carried out on a typical "consumer" profile, with a $8 \mathrm{~m}^{2}$ photovoltaic plant installed.

To understand the behavior of a smart node characterized by large input of power in the grid (typical "prosumer" profile) with respect to the self-consumption power, tests were carried out on a domestic user with a $24 \mathrm{~m}^{2} \mathrm{PV}$ panel plant installed.

Finally, a smart node for an industrial user was investigated. The node is characterized by a $80 \mathrm{~m}^{2}$ paneled area, with a peak power of about $10 \mathrm{~kW}$.

The smart node system parameters have to be monitored during the simulated period in order to understand the energy balance and the interaction of the node with the grid.

To evaluate the system performance, the following quantities were monitored.

- $\quad$ Energy employed by the user in the monitored period;

- Energy input from the grid to the node in the monitored period;

- Energy output from the node to the grid in the monitored period;

- Energy input from the photovoltaic panel in the monitored period;

- $\quad$ Energy provided to the electric vehicle battery in the monitored period;

- Energy loss in system stationary battery in the monitored period;

- Gross energy in input to the battery in the monitored period;

- Gross energy output from the battery in the monitored period;

- Battery efficiency, defined as the ratio between gross battery output and gross battery input energies.

- $\quad$ Battery to user energy ratio $(E)$, defined as the ratio between gross energy output from the battery and energy required by the user; this index gives an idea of how much energy flows in battery during operation.

- Grid power distortion factor $(D)$, defined in Equation 9:

$D=\frac{\left(P_{\text {Grid }}\right)_{\max }-\left(P_{\text {Grid }}\right)_{\min }}{\left(P_{\text {Grid }}\right)_{\text {mean }}}$

being $\left(P_{\text {Grid }}\right)_{\max }$ the maximum positive grid power peak and $\left(P_{\text {Grid }}\right)_{\min }$ the minimum power peak. This factor provides information on how much the node disturbs the grid with its presence.

- $\quad$ Battery engagement index or battery frequency of intervention $(F)$, defined as the ratio between maximum battery chemical power and battery energetic capacity. This index, expressed in $\mathrm{kW} / \mathrm{kWh}$, is important as it indicates how much the battery is stressed, giving an idea of how many cycles the battery must bear per each hour of operation.

The tests on the model have been carried out for the month of June.

\subsection{Domestic User with 1 kW Panel}

The first tests were carried out on a user equipped with a photovoltaic plant rated $1 \mathrm{~kW}$ peak power.

The power profile of the basic domestic user, derived from the user's model described in Section 2, is represented in Figure $\mathbf{8}$. The user consumes an energy amount of $434.3 \mathrm{kWh}$ per month.

The user simply connected to the electric grid without panel or battery (basic node) is characterized by a grid distortion factor of 4.97 .

In Figure 9 are represented the grid power and the panel power for 3 consecutive days, for the system without storage. The panel power line shows the influence of the clouds passage. As visible, the grid power is positive (i.e. enters in the node) above all in the evening and during the night, while during the day the system tends mostly to supply power to the grid.

In Figure $\mathbf{1 0}$ can be observed the diagram of panel power and grid power with time for the system with battery managed in grid-smoothing mode. As visible, the grid power range is between -1 and $+1 \mathrm{~kW}$, whereas in the case without battery the grid power ranged between -1 and $+3 \mathrm{~kW}$. 


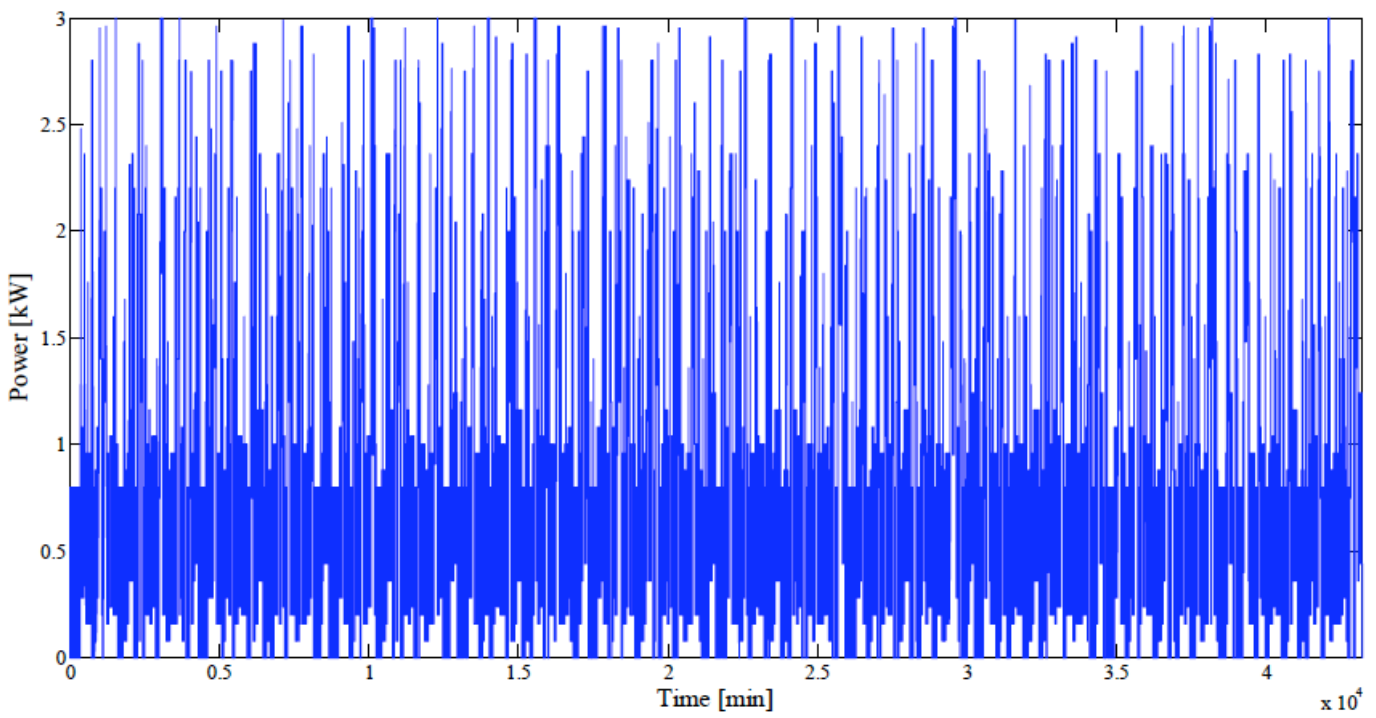

Figure 8: Basic domestic user power profile with time.

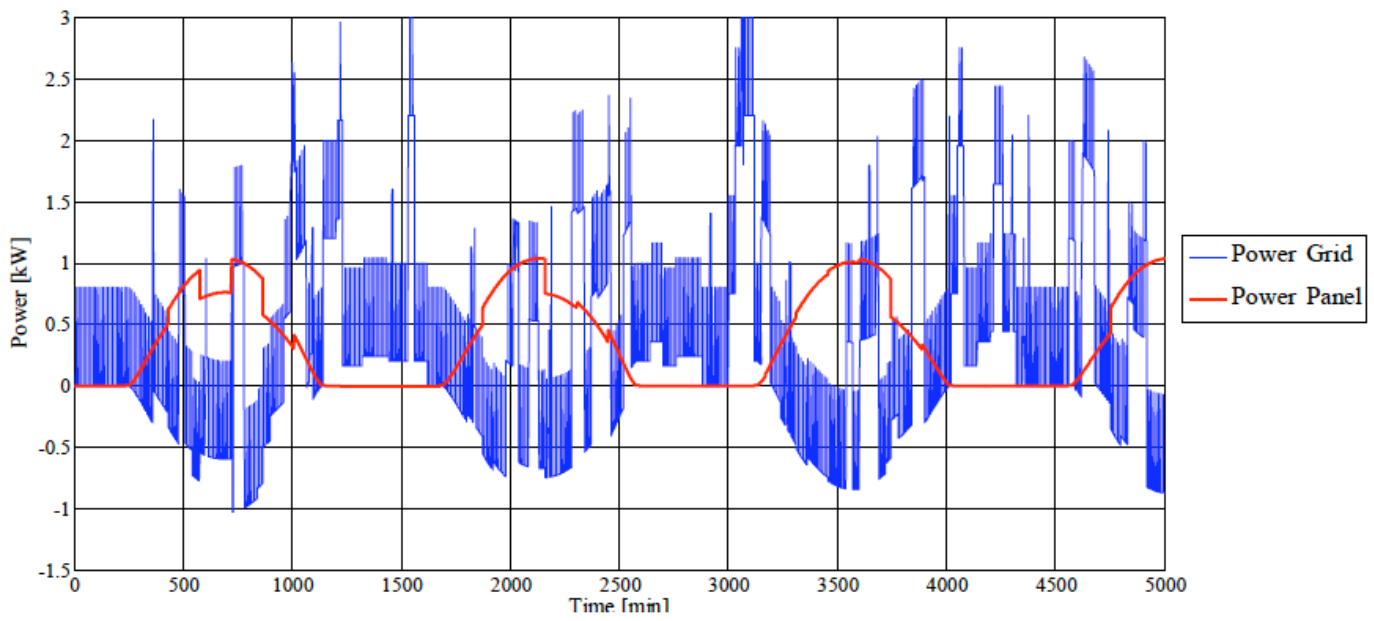

Figure 9: Power profiles for the grid and for the PV panel with time, in the system without battery.

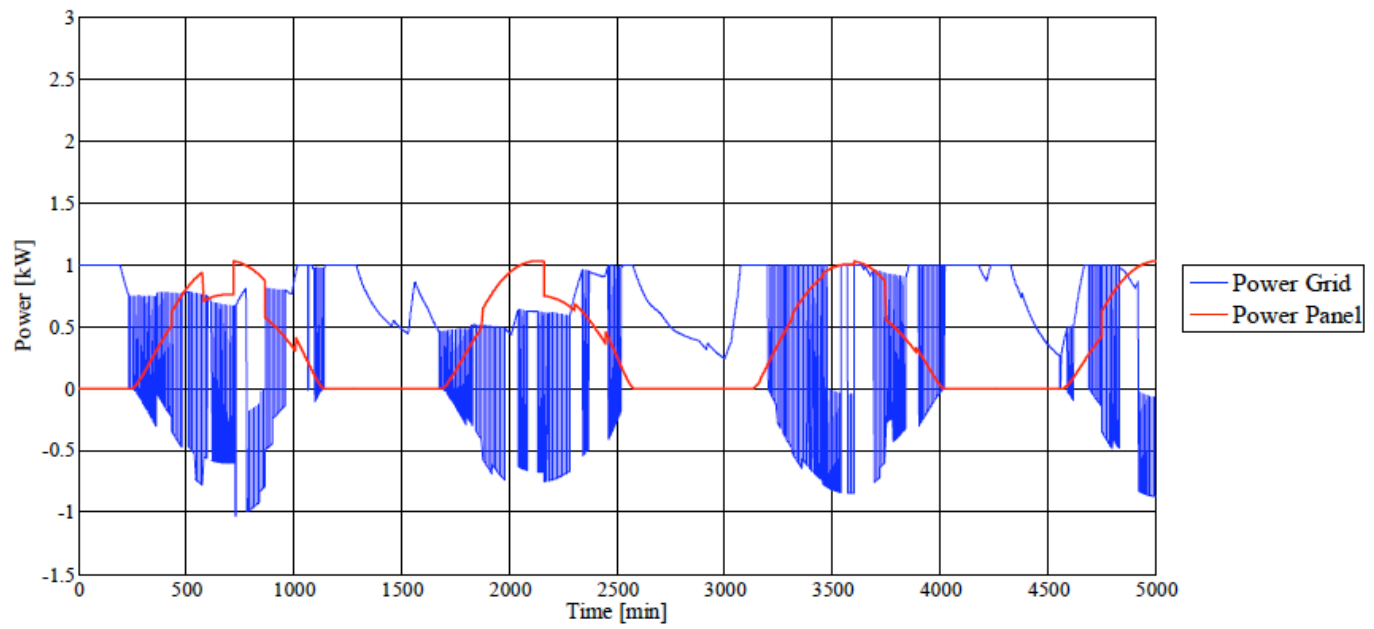

Figure 10: Power profiles for the grid and for the PV panel with time, in the system with battery managed in grid-smoothing mode. 


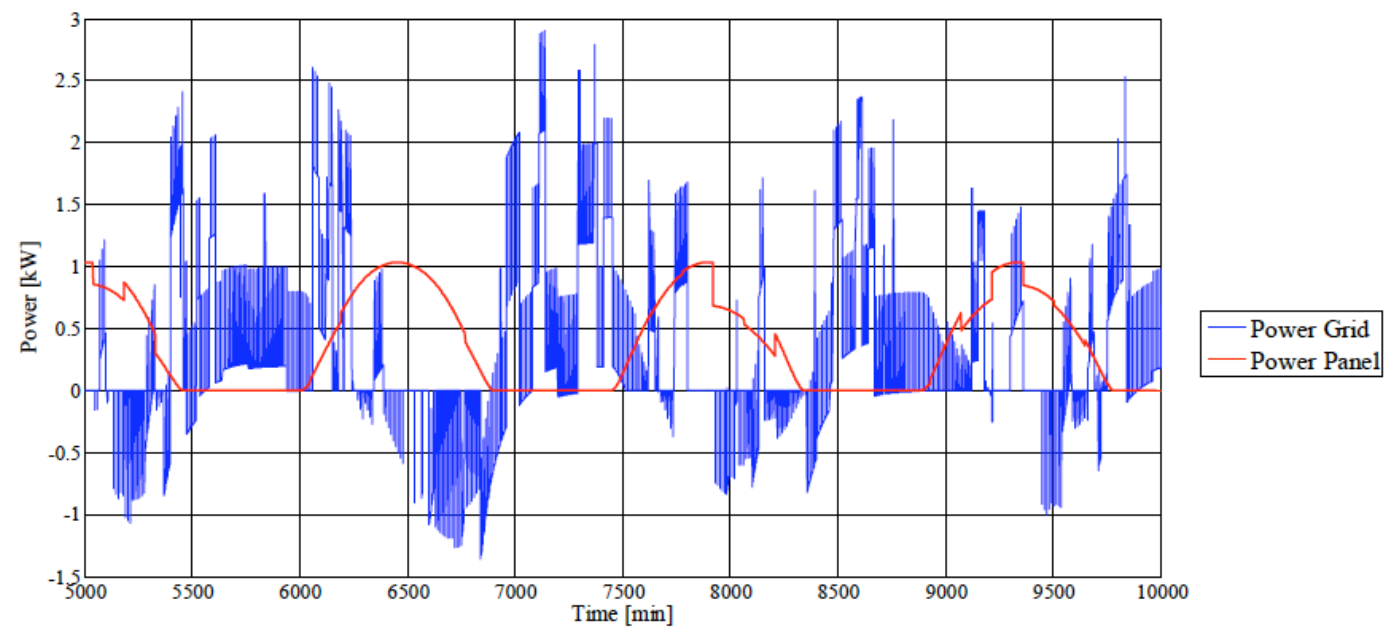

Figure 11: Power profiles for the grid and for the PV panel with time, in the system with battery managed in self-consumption mode.

In Figure $\mathbf{1 1}$ is reported the diagram of panel and grid power for the system with battery managed in the self-consumption mode. It is clearly visible that, during the day, the grid power values are rather often equal to zero, indicating that the algorithm operates in the direction to self-consume the power produced by the panel. The power values are comprised between -1.5 and $3 \mathrm{~kW}$. The value of $-1.5 \mathrm{~kW}$ is reached as the battery state of charge is too high and the control algorithm needs to discharge the battery, delivering power to the grid.

In Figure $\mathbf{1 2}$ is represented the gross power flows at the inlet and outlet of the battery. As visible, the highest power peaks occur for the battery outlet power, reaching about $-2 \mathrm{~kW}$ values.

In Table $\mathbf{1}$ are presented the main results of the simulations for the system. The table provides the comparison between the node with the only panel, and the same with panel and battery, the latter being managed both in grid-smoothing mode and in selfconsumption mode. The tests refer to the month of June.

The configuration with the only panel requires an energy amount from the grid equal to $308.1 \mathrm{kWh}$ and supplies to the grid $133.4 \mathrm{kWh}$. The energy provided by the panel is equal to $259.7 \mathrm{kWh}$. In this configuration, the calculated value of the grid distortion factor $D$ is equal to 16.61 , which is more than 3 times the $D$ value of the basic node (4.97).

The configuration with storage managed in the gridsmoothing mode requires from the grid an amount of energy slightly higher than the system with the only panel (330.0 kWh vs. $308.1 \mathrm{kWh}$ ), and this is due to the higher losses encountered owing to the battery

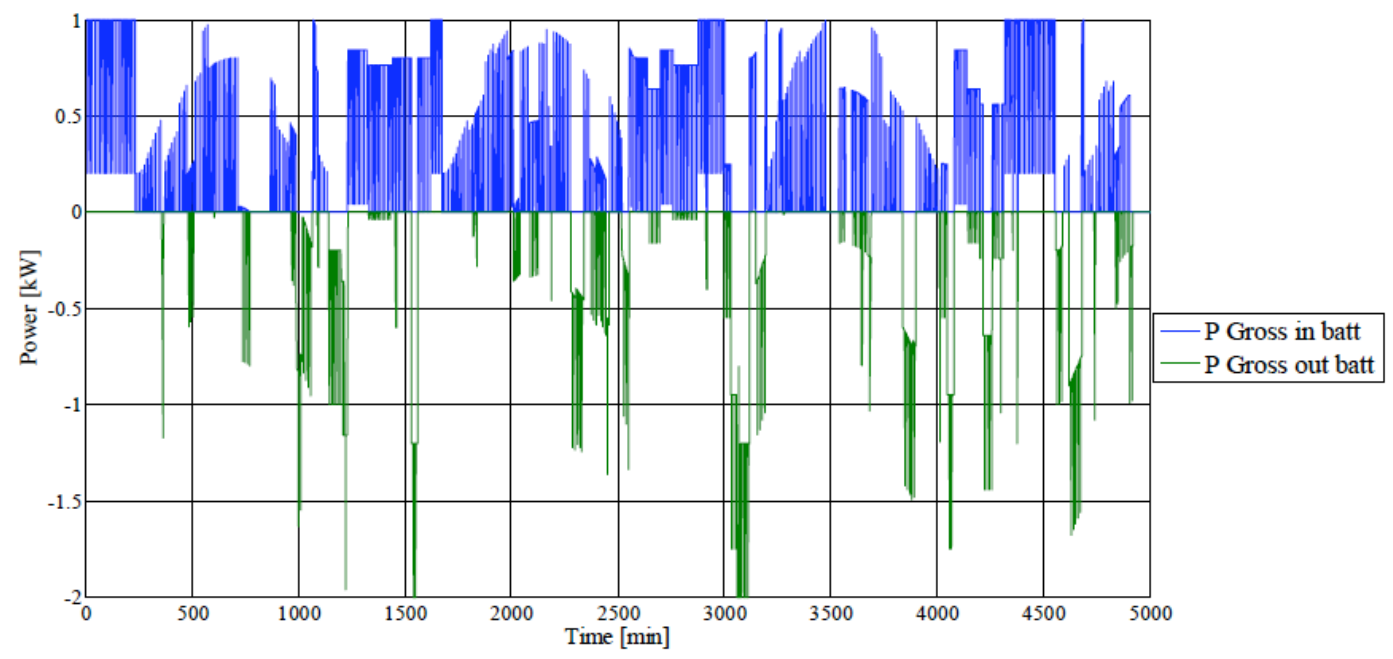

Figure 12: Gross battery power input and output. 
Table 1: Main Performance Parameters for the System with $1 \mathrm{~kW}$ PV Panel and without Battery, with PV Panel and Battery in the Grid-Smoothing Mode and in the Self-Consumption Mode

\begin{tabular}{|c|c|c|c|c|}
\hline & & Basic+PV Panel & $\begin{array}{c}\text { Basic+PV Panel+Battery } \\
\text { (Grid-Smoothing Mode) }\end{array}$ & $\begin{array}{c}\text { Basic+PV Panel+Battery (Self- } \\
\text { Consumption Mode) }\end{array}$ \\
\hline \hline User Energy & {$[\mathrm{kWh}]$} & 434,33 & 434,33 & 434,33 \\
\hline Energy from Grid & {$[\mathrm{kWh}]$} & 308,08 & 330,00 & 229,74 \\
\hline Energy to Grid & {$[\mathrm{kWh}]$} & 133,44 & 133,44 & 25,74 \\
\hline PV panel Energy & {$[\mathrm{kWh}]$} & 259,70 & 259,70 & 0,00 \\
\hline Electric Vehicle Energy & {$[\mathrm{kWh}]$} & 0,00 & 0,00 & 20,31 \\
\hline Energy Lost & {$[\mathrm{kWh}]$} & 0,00 & 19,21 & 133,44 \\
\hline Gross Energy battery input & {$[\mathrm{kWh}]$} & 0,00 & 136,01 & 114,08 \\
\hline $\begin{array}{c}\text { Gross Energy battery } \\
\text { output }\end{array}$ & {$[\mathrm{kWh}]$} & 0,00 & 114,10 & 0,85 \\
\hline $\begin{array}{c}\text { Battery Efficiency } \\
\text { E (Battery to user energy } \\
\text { ratio) }\end{array}$ & {$[-]$} & $\mathrm{NC}$ & 0,84 & 0,26 \\
\hline D (Grid Distortion Factor) & {$[-]$} & $\mathrm{NC}$ & 0,26 & 17,99 \\
\hline F (Battery Engagement \\
Factor)
\end{tabular}

presence. Instead, the amount of energy supplied to the grid is equal to that of the system equipped with the only panel. In this case, the grid distortion factor reduces to 7.43 vs. 16.61 of the panel-only configuration.

The system configuration with battery managed in the self-consumption mode has a lower energy absorbed from the grid (229.74 kWh) and also a lower energy supplied to the grid $(35.74 \mathrm{kWh})$. The grid distortion factor increases up to almost 18, indicating that this battery management mode is not suitable for purposes of grid power profile smoothing.
The gross energy in and out of the storage and the energy lost in battery result almost equal for the two configurations equipped with battery. The two batteries seem to operate in a similar manner from the energetic point of view, which is also visible from the $E$ parameter (battery to user energy ratio) and this implies that also the battery efficiencies result very similar for the two cases $(0.85$ vs. 0.84$)$. The battery engagement index $F$ results lower for the self-consumption configuration ( 0.37 vs. 0.45 of the grid-smoothing mode), indicating a lower stress for the battery managed in the selfconsumption mode.

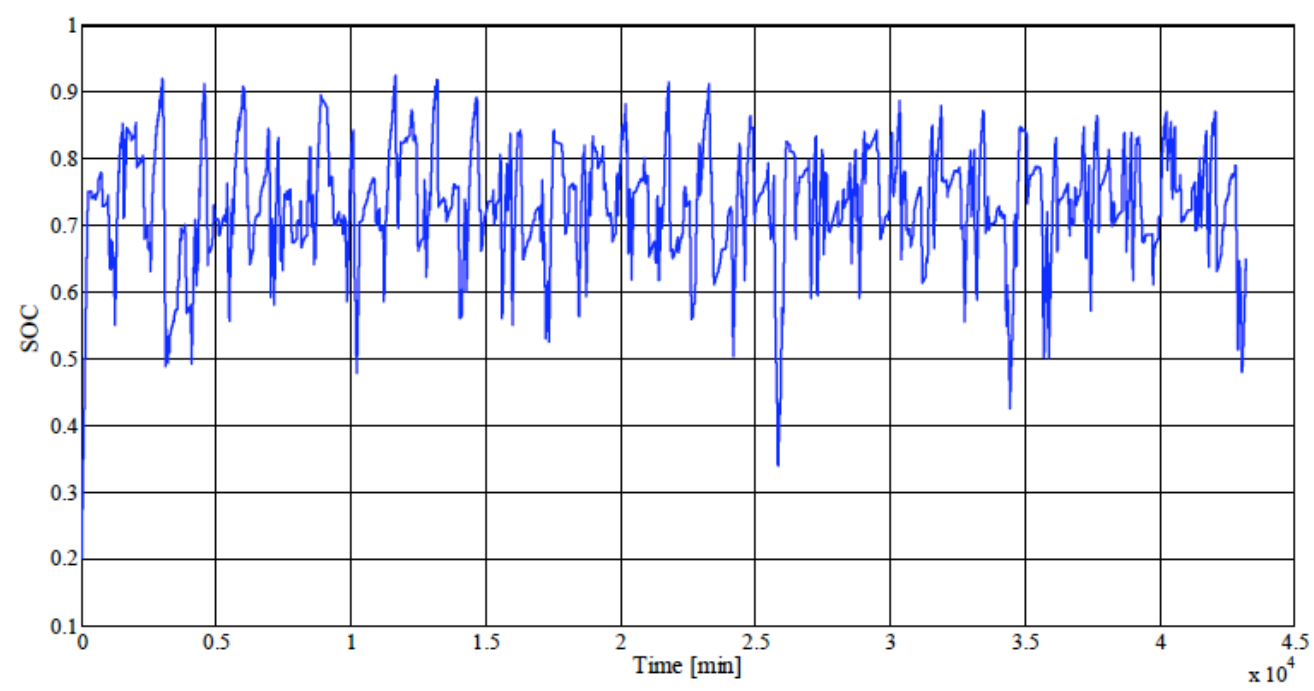

Figure 13: Battery state of charge for the system managed in grid-smoothing mode. 


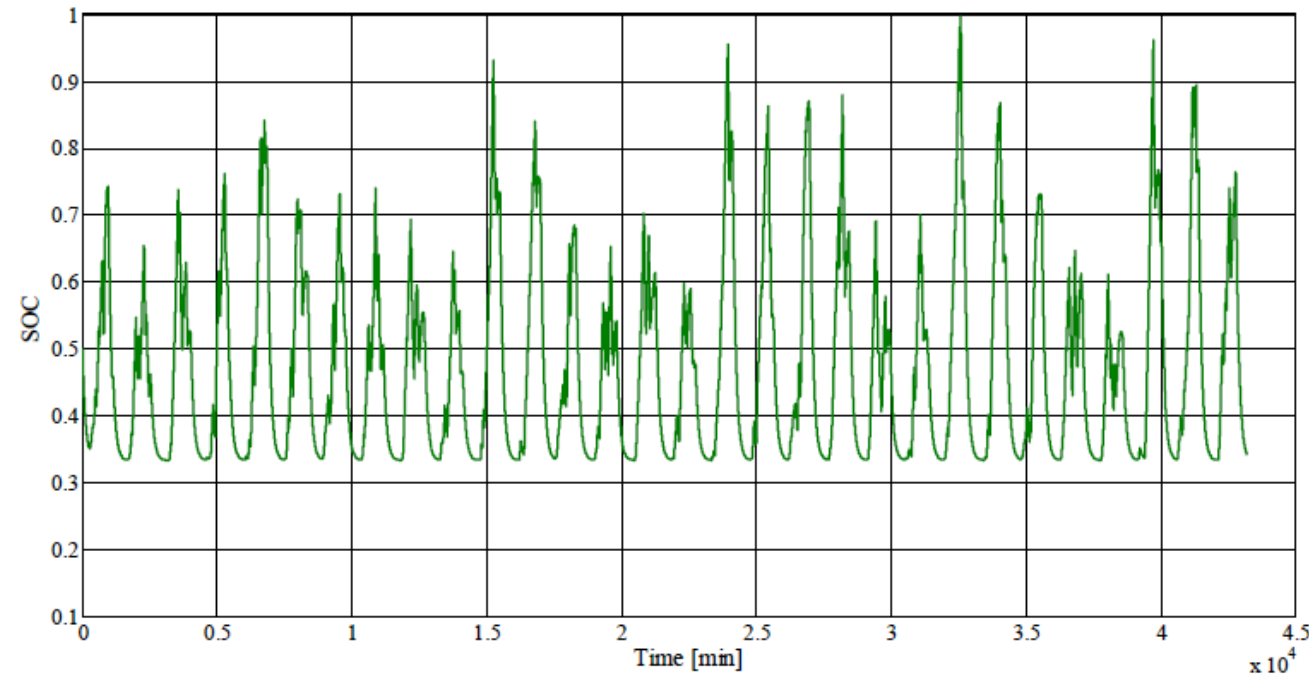

Figure 14: Battery state of charge for the system managed in the self-consumption mode.

The two following Figures $\mathbf{1 3}$ and $\mathbf{1 4}$ present the battery state of charge with time for the grid-smoothing mode and for the self-consumption mode.

As visible, the diagrams are rather different, highlighting a trend of the self-consumption mode storage to operate with a daily frequency, whereas in the grid-smoothing management the state of charge changes with a higher frequency.

Table 2 presents the results of the system equipped with stationary storage and electric vehicle, in grid smoothing mode and self consumption mode. In the table, is carried out a comparison of the system with and without electric vehicle in the adjacent columns. In the tests, the electric vehicle was set in order to have a monthly mileage of about $900 \mathrm{~km}$, with a consumption of $0.074 \mathrm{kWh} / \mathrm{km}$. The low value of the vehicle consumption is due to the fact that the chosen vehicle was a micro-electric car, for example a Renault Twizy.

As expected, the presence of the electric vehicle (EV) increases the energy required from the grid and reduces the energy supplied to the grid in both the battery management modes.

The energy loss results similar with or without the electric vehicle, both in grid-smoothing mode and in self-consumption mode.

Table 2: Main Performance Parameters for the Domestic System with 1 kW PV Panel: Comparison between Systems with and without Electric Vehicle

\begin{tabular}{|c|c|c|c|c|c|}
\hline & & \multicolumn{2}{|c|}{$\begin{array}{c}\text { Basic+PV Panel+Battery (Grid- } \\
\text { SMOOTHING MODE) }\end{array}$} & \multicolumn{2}{|c|}{$\begin{array}{c}\text { Basic+PV Panel+Battery (Self- } \\
\text { Consumption Mode) }\end{array}$} \\
\hline & & No EV & EV & No EV & EV \\
\hline User Energy & {$[\mathrm{kWh}]$} & 434,33 & 434,33 & 434,33 & 434,33 \\
\hline Energy from Grid & {$[\mathrm{kWh}]$} & 330,00 & 383,61 & 229,74 & 290,22 \\
\hline Energy to Grid & {$[\mathrm{kWh}]$} & 133,44 & 117,52 & 35,74 & 27,59 \\
\hline PV panel Energy & {$[\mathrm{kWh}]$} & 259,70 & 259,70 & 259,70 & 259,70 \\
\hline Electric Vehicle Energy & {$[\mathrm{kWh}]$} & 0,00 & 68,86 & 0,00 & 68,86 \\
\hline Energy Lost & {$[\mathrm{kWh}]$} & 19,21 & 21,00 & 20,31 & 18,29 \\
\hline Gross Energy battery input & {$[\mathrm{kWh}]$} & 136,01 & 152,31 & 133,44 & 117,52 \\
\hline Gross Energy battery output & {$[\mathrm{kWh}]$} & 114,10 & 129,72 & 114,08 & 98,38 \\
\hline Battery Efficiency & {$[-]$} & 0,84 & 0,85 & 0,85 & 0,84 \\
\hline E (Battery to user energy ratio) & {$[-]$} & 0,26 & 0,26 & 0,26 & 0,20 \\
\hline D (Grid Distortion Factor) & {$[-]$} & 7,43 & 5,49 & 17,99 & 15,82 \\
\hline F (Battery Engagement Factor) & {$[\mathrm{kW} / \mathrm{kWh}]$} & 0,45 & 0,60 & 0,37 & 0,35 \\
\hline
\end{tabular}


The battery efficiency results similar for the two management modes, attesting between the values of 0.84 and 0.85 .

In grid smoothing mode, the battery to user energy ratio $E$ results equal with or without the electric vehicle, while for the self-consumption mode the presence of the electric vehicle involves a decrease of the mentioned parameter $(0.20$ vs. 0.26$)$, indicating that less energy flows through the battery.

The presence of the electric vehicle involves a decrease of the grid distortion factor $D$ in both the battery management modes. In particular, in the gridsmoothing mode the $D$ value decreases of $26.1 \%$, while for the self-consumption mode the decrease results of the $12.1 \%$.

The battery engagement index (or battery frequency of intervention) $F$ increases in presence of the electric vehicle for the grid smoothing mode $(0.60$ vs. 0.45$)$, while for the self consumption mode the value keeps almost equal with or without the electric vehicle, with a slight decreasing trend (0.35 vs. 0.37).

Also, the effect of the battery size was tested, comparing the performances of two systems equipped with batteries of $6 \mathrm{kWh}$ and $12 \mathrm{kWh}$ energetic capacity. The results are presented in the following figures and in Table 3.

As visible, the energy balance and the losses remain almost unaltered for the two battery sizes, both in grid-smoothing mode and in self-consumption mode.
As shown in the table, the capacity increase involves a slight decrease of the battery efficiency in both control modes, while the frequency of intervention $F$ results very decreased with the larger battery, above all in the self consumption mode, indicating a lower stress of the component.

The battery to user energy ratio $E$ does not seem to change significantly for the two battery sizes.

The battery size has few influence in terms of grid distortion factor $D$ for the system managed in grid smoothing mode, while for the self-consumption mode the increase in energetic capacity provides a decrease of the grid distortion factor from 17.99 to $14.33(-20 \%)$.

\subsection{User with 3 kW Panel}

A user mounting a $3 \mathrm{~kW}$ panel (about $24 \mathrm{~m}^{2}$ of paneled area) can be defined as a "prosumer", intended as a user, whose panel production overcomes the subject's consumption, providing a large energy input in the grid. The photovoltaic panel of the "prosumer" subject simulated in the tests was able to produce, in the month of June, an energy amount of $779 \mathrm{kWh}$, exceeding energy monthly consumed (434.33 kWh). The system with storage is equipped with a battery having $6 \mathrm{kWh}$ energetic capacity.

Table 4 provides the main quantities of the test, comparing the system with the only panel with the systems equipped with battery, managed in the gridsmoothing and self-consumption modes.

Table 3: Main Performance Parameters for the System with 1 kW Panel: Battery Size Influence

\begin{tabular}{|c|c|c|c|c|c|}
\hline \multirow[b]{2}{*}{ Battery size } & & \multicolumn{2}{|c|}{$\begin{array}{c}\text { Basic+PV Panel+Battery (Grid- } \\
\text { SMOOTHING MODE) }\end{array}$} & \multicolumn{2}{|c|}{$\begin{array}{c}\text { Basic+PV Panel+Battery (Self- } \\
\text { Consumption Mode) }\end{array}$} \\
\hline & & $6 \mathrm{kWh}$ & 12 kWh & $6 \mathrm{kWh}$ & $12 \mathrm{kWh}$ \\
\hline User Energy & {$[\mathrm{kWh}]$} & 434,33 & 434,33 & 434,33 & 434,33 \\
\hline Energy from Grid & [kWh] & 330,00 & 334,47 & 229,74 & 225,76 \\
\hline Energy to Grid & {$[\mathrm{kWh}]$} & 133,44 & 133,44 & 35,74 & 27,37 \\
\hline PV panel Energy & {$[\mathrm{kWh}]$} & 259,70 & 259,70 & 259,70 & 259,70 \\
\hline Electric Vehicle Energy & {$[\mathrm{kWh}]$} & 0,00 & 0,00 & 0,00 & 0,00 \\
\hline Energy Lost & {$[\mathrm{kWh}]$} & 19,21 & 19,25 & 20,31 & 20,43 \\
\hline Gross Energy battery input & {$[\mathrm{kWh}]$} & 136,01 & 143,19 & 133,44 & 133,44 \\
\hline Gross Energy battery output & {$[\mathrm{kWh}]$} & 114,10 & 116,81 & 114,08 & 109,70 \\
\hline Battery Efficiency & {$[-]$} & 0,84 & 0,82 & 0,85 & 0,82 \\
\hline $\mathrm{E}$ (Battery to user energy ratio) & {$[-]$} & 0,26 & 0,27 & 0,26 & 0,25 \\
\hline D (Grid Distortion Factor) & {$[-]$} & 7,43 & 7,27 & 17,99 & 14,33 \\
\hline F (Battery Engagement Factor) & {$[\mathrm{kW} / \mathrm{kWh}]$} & 0,45 & 0,22 & 0,37 & 0,10 \\
\hline
\end{tabular}


Table 4: Main Performance Parameters for System with 3 kW PV Panel

\begin{tabular}{|c|c|c|c|c|}
\hline & & Panel 3 kW & $\begin{array}{c}\text { Panel } 3 \text { kW + Storage } 6 \\
\text { kWh Grid Smoothing }\end{array}$ & $\begin{array}{l}\text { Panel } 3 \text { kW + Storage } 6 \\
\text { kWh Self Consumption }\end{array}$ \\
\hline User Energy & {$[\mathrm{kWh}]$} & 434,33 & 434,33 & 434,33 \\
\hline Energy from Grid & [kWh] & 218,86 & 236,38 & 148,07 \\
\hline Energy to Grid & [kWh] & 563,61 & 563,61 & 473,00 \\
\hline PV panel Energy & {$[\mathrm{kWh}]$} & 779,08 & 779,08 & 779,08 \\
\hline Electric Vehicle Energy & {$[\mathrm{kWh}]$} & 0,00 & 0,00 & 0,00 \\
\hline Energy Lost & {$[\mathrm{kWh}]$} & 0,00 & 14,98 & 18,91 \\
\hline Gross Energy battery input & {$[\mathrm{kWh}]$} & & 105,86 & 146,87 \\
\hline Gross Energy battery output & {$[\mathrm{kWh}]$} & & 88,34 & 127,06 \\
\hline Battery Efficiency & {$[-]$} & NC & 0,83 & 0,87 \\
\hline $\mathrm{E}$ (Battery to user energy ratio) & {$[-]$} & NC & 0,20 & 0,29 \\
\hline D (Grid Distortion Factor) & {$[-]$} & $-12,72$ & $-9,00$ & $-13,52$ \\
\hline F (Battery Engagement Factor) & {$[\mathrm{kW} / \mathrm{kWh}]$} & NC & 0,45 & 0,44 \\
\hline
\end{tabular}

As expected, the energy absorbed from the grid is largely lower than that supplied to the grid. The trend of the data is similar to the previous tests: the energy absorbed from the grid for the grid-smoothing mode is higher than that of the case equipped with the only panel (236.38 kWh vs. $218.86 \mathrm{kWh}$ ); the energy supplied to the grid is equal for the basic and for the grid smoothing case $(563.61 \mathrm{kWh})$, while the selfconsumption case takes from the grid $148.07 \mathrm{kWh}$ and supplies $473.0 \mathrm{kWh}$, about $90 \mathrm{kWh}$ less than the two other systems. The energy losses are comparable for the two configurations equipped with battery, although the self consumption mode shows a higher value than the grid-smoothing mode (about $15 \mathrm{kWh}$ vs. about 19 $\mathrm{kWh}$ ).

The battery efficiency for the self-consumption mode results higher than that of the grid-smoothing mode (0.87 vs. 0.83$)$.
The battery to user energy ratio $E$ is higher for the self-consumption mode $(0.29$ vs. 0.20 of the gridsmoothing mode), indicating that a higher amount of energy flows in the battery. The battery intervention frequency $F$ results similar for the two cases.

In the "prosumer" case the $D$ parameter, for its definition, is negative; being the mean grid power negative (the amount of energy supplied to the grid is higher than that taken from the grid due to the oversized photovoltaic panel). As in the previous cases, the grid distortion factor results decreased with respect to the system equipped with only panel for the system providing battery managed in grid-smoothing mode ( -9 vs. -12.72 , with a decrease of about $29 \%$ ). It results slightly increased for the self-consumption mode ( -13.52 vs. -12.72 , with an increase of $6 \%)$.

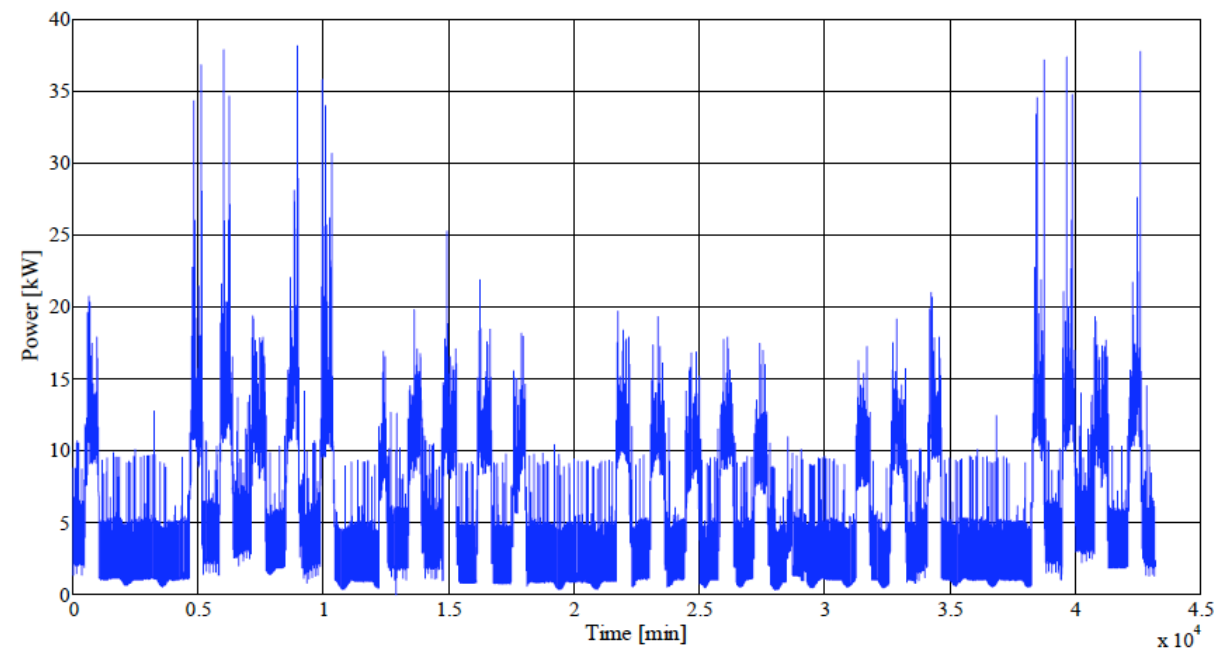

Figure 15: Measured power profile of the industrial user. 


\subsection{Industrial User}

In Figure $\mathbf{1 5}$ is presented the industrial user power absorbed from the grid, measured during the month of March. As visible, the peak power reached is about 38 $\mathrm{kW}$; the monthly consumption is $3274 \mathrm{kWh}$.

The data analysis highlights that for most of the time (about $27000 \mathrm{~min}$ ) the power absorbed by the small industry is lower or equal than $5 \mathrm{~kW}$.

Table 5 presents the main parameters of the simulations carried out for the industrial user; the industrial node configurations were: basic, composed by the only user connected to the grid; basic with PV panel; basic with PV panel and storage (of $22 \mathrm{kWh}$ energetic capacity) in grid-smoothing mode; basic with $\mathrm{PV}$ panel and storage in self-consumption mode;

As visible, the presence of the panel reduces the energy required from the grid with respect to the basic plant, of about $1050 \mathrm{kWh}$, and provides an amount of energy to the grid equal to $775 \mathrm{kWh}$.

The system with storage in self-consumption mode requires less energy from the grid $(-184 \mathrm{kWh})$ and provides less energy to the grid $(-160 \mathrm{kWh})$ than the system in grid-smoothing mode.

The energy loss in battery for the self-consumption mode is lower than that for the grid-smoothing mode (52 kWh vs. $35 \mathrm{kWh}$ ).

The battery efficiency is higher for the system managed in the self-consumption mode, reaching a value of 0.9 , against the value of 0.82 for the gridsmoothing mode.

The battery to user energy ratio $E$ results low (between 0.08 and 0.09) for both the battery management systems, indicating that the energy flow in battery is limited. The battery engagement factor is rather high for the system in grid-smoothing mode, reaching a value of $1.17 \mathrm{~kW} / \mathrm{kWh}$. For the selfconsumption mode the $E$ value maintains to lower values $(0.43)$, in line with the previous simulations.

As expected, the grid distortion factor $D$ is much increased in the configuration with panel with respect to the basic case (8.58 vs. 22.05). The system with panel and storage in the grid-smoothing mode reduces the distortion value down to 10.3 , whereas in the selfconsumption mode the distortion rises up to values slightly higher than the system with the sole panel (22.7).

\section{CONCLUSIONS}

This paper presented the results of a simulation model finalized to understand the operation of a smart node connected to the electric grid in different configurations; the node components are the user, the PV panel, the storage and the electric vehicle.

Two user sizes were tested: a typical domestic user ( $3 \mathrm{~kW}$ maximum power absorbed from the grid) and an industrial user, whose consumption profile was measured experimentally. The domestic user was tested both equipped with a $1 \mathrm{~kW}$ peak power panel

Table 5: Main Performance Parameters for the Industrial User

\begin{tabular}{|c|c|c|c|c|c|}
\hline & & Basic & Panel & $\begin{array}{c}\text { Panel + Storage } \\
\text { Grid Smoothing }\end{array}$ & $\begin{array}{c}\text { Panel + Storge } \\
\text { Self Consumption }\end{array}$ \\
\hline \hline User Energy & {$[\mathrm{kWh}]$} & 3274,72 & 3274,72 & 3274,72 & 3274,72 \\
\hline Energy from Grid & {$[\mathrm{kWh}]$} & 3274,72 & 2223,44 & 2280,56 & 2096,42 \\
\hline Energy to Grid & {$[\mathrm{kWh}]$} & 0,00 & 775,03 & 775,03 & 615,58 \\
\hline PV panel Energy & {$[\mathrm{kWh}]$} & 0,00 & 1826,39 & 1826,39 & 1826,39 \\
\hline Electric Vehicle Energy & {$[\mathrm{kWh}]$} & 0,00 & 0,00 & 0,00 & 0,00 \\
\hline Energy Lost & {$[\mathrm{kWh}]$} & 0,00 & 0,00 & 52,06 & 35,32 \\
\hline Gross Energy battery input & {$[\mathrm{kWh}]$} & 0,00 & 0,00 & 321,42 & 316,39 \\
\hline Gross Energy battery output & {$[\mathrm{kWh}]$} & 0,00 & 0,00 & 264,31 & 283,94 \\
\hline Battery Efficiency & {$[-]$} & NC & NC & 0,82 \\
\hline E (Battery to user energy ratio) & {$[-]$} & NC & NC & 0,08 & 0,90 \\
\hline D (Grid Distortion Factor) & {$[-]$} & 8,58 & 22,05 & 10,33 & 0,09 \\
\hline F (Battery Engagement Factor) & {$[\mathrm{kW} / \mathrm{kWh}]$} & NC & NC & 1,17 \\
\hline
\end{tabular}


and with a $3 \mathrm{~kW}$ peak power panel, to understand the influence of the PV panel size on the node performance.

The tests provided the simulation of two different strategies for the management of the node equipped with battery: the grid-smoothing mode, addicted to carry out the smoothing of the disturbances caused by the node to the electric grid and the self-consumption mode, addicted to maximize the self-consumption of the energy produced by the PV panel.

The results indicate that the system with panel and battery managed in the grid-smoothing mode provides a reduction of the grid distortion factor ranging between $30 \%$ and $55 \%$. The system managed in the selfconsumption mode provides a decrease of the energy required from the grid and of the energy supplied to the grid promoting the panel energy self-consumption, but with this control modality the node produces high disturbance to the grid, as if the battery was not installed.

The battery size effect was tested, by simulating for the domestic user two batteries with energetic capacity of $6 \mathrm{kWh}$ and $12 \mathrm{kWh}$. The tests provided similar results, except for the battery efficiency parameter (which tends to decrease with the larger battery) and for the battery engagement factor. The latter showed a strong decrease for the larger battery, indicating a lower stress on the component.

The electric vehicle presence, as expected, increases the consumptions, but seems to reduce the grid distortion factor.

The node equipped with a $3 \mathrm{~kW}$ PV panel showed similar behavior as the smaller $1 \mathrm{~kW}$ one, except for the energy balance, since this node configuration supplies higher energy to the grid than that absorbed. In this case, the grid distortion factor showed negative values.

For the industrial user, similar considerations as for the domestic user can be done. Particular attention should be paid to the battery health in the gridsmoothing mode, as the battery engagement factor showed a rather high value (1.17).

\section{NOMENCLATURE}

$\begin{array}{lll}\text { Symbol } & \text { Description } & {[\text { Units] }} \\ \text { D } & \text { Frid distortion factor } & {[-]} \\ \text { E } & \text { Battery to user energy ratio } & {[-]} \\ \text { F } & \text { Battery engagement factor } & {[-]} \\ \text { P } & \text { Power } & {[\mathrm{kW}]} \\ \text { SOC } & \text { State of charge } & {[-]}\end{array}$

\section{REFERENCES}

[1] Mohd A, Ortjohann E, Schmelter A, Hamsic N, Morton D. Challenges in integrating distributed energy storage systems into future smart grids. Proceedings of International Symposium on Industrial Electronics; 2008. ISIE 2008, IEEE p. 1627-1632 Cambridge.

[2] Yang Z, Zang J, Kinter-Meyer MCW, et al. Electrochemical energy storage for green grid. Chem Rev 2011; 111: 3577613. http://dx.doi.org/10.1021/cr100290v

[3] Cao S, Siren K. Impact of simulation time-resolution on the matching of PV production and household electric demand. Applied Energy 2014; 128: 192-208. http://dx.doi.org/10.1016/j.apenergy.2014.04.075

[4] Crosa G, Lubiano M, Trucco A. Modeling of PV-powered water electrolyzers. Proceedings of ASME Turbo Expo 2006, vol. 2 Barcelona, Spain May 8-11.

[5] Hofierka J, Suri M. The solar radiation model for open source GIS: implementation and applications. Proceedings of the Open Source GIS Grass users conference 2002 Trento, 1113 September 2002.

[6] Tremblay O, Dessaint LA. Experimental validation of a battery dynamic model for EV applications. World Electric Vehicle Journal 2009; 3. ISSN 2032-6653.

[7] Tremblay O, Dessaint LA, Dekkiche AI. A generic battery model for the dynamic simulation of hybrid electric vehicles. Proceedings of IEEE Vehicle Power and Propulsion Conference, 2007.

[8] Shepherd CM. Design of primary and secondary cells - part 2: an equation describing battery discharge. Journal of Electrochemical Society 1965; 112.

[9] Capasso C, Veneri O. Experimental analysis on the performance of lithium based batteries for road full electric and hybrid vehicles. Applied Energy 2014; 136: 921-30. http://dx.doi.org/10.1016/j.apenergy.2014.04.013

[10] Scrosati B, Garche J. Lithium batteries: status, prospects and future. J Power Sources 2010; 195: 2419-30. http://dx.doi.org/10.1016/i.jpowsour.2009.11.048

\section{DOl: http://dx.doi.org/10.6000/1929-6002.2014.03.04.7}

(C) 2014 Damiani et al.; Licensee Lifescience Global.

This is an open access article licensed under the terms of the Creative Commons Attribution Non-Commercial License (http://creativecommons.org/licenses/by-nc/3.0/) which permits unrestricted, non-commercial use, distribution and reproduction in any medium, provided the work is properly cited. 